\title{
Central Nervous System Involvement in Trichinellosis: A Systematic Review
}

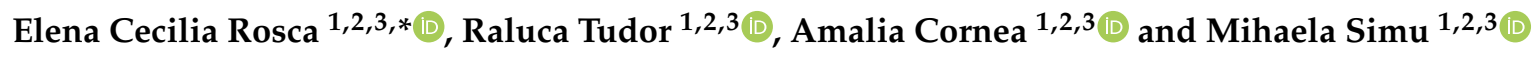 \\ 1 Victor Babes University of Medicine and Pharmacy Timisoara, Eftimie Murgu Sq. No. 2, \\ 300041 Timisoara, Romania; tudor.raluca@yahoo.com (R.T.); amalia.cornea@yahoo.com (A.C.); \\ mihaelasimu6713@gmail.com (M.S.) \\ 2 Department of Neurology, Clinical Emergency County Hospital Timisoara, Bd. Iosif Bulbuca No. 10, \\ 300736 Timisoara, Romania \\ 3 Neuroscience Research Center Timisoara, Clinical Emergency County Hospital Timisoara, \\ Bd. Iosif Bulbuca No. 10, 300736 Timisoara, Romania \\ * Correspondence: roscacecilia@yahoo.com; Tel.: +40-746173794
}

Citation: Rosca, E.C.; Tudor, R.;

Cornea, A.; Simu, M. Central Nervous System Involvement in Trichinellosis: A Systematic Review. Diagnostics 2021, 11, 945. https://doi.org/ 10.3390/diagnostics11060945

Academic Editor: Javier Fernández

Received: 29 March 2021

Accepted: 22 May 2021

Published: 25 May 2021

Publisher's Note: MDPI stays neutral with regard to jurisdictional claims in published maps and institutional affiliations.

Copyright: (c) 2021 by the authors. Licensee MDPI, Basel, Switzerland. This article is an open access article distributed under the terms and conditions of the Creative Commons Attribution (CC BY) license (https:// creativecommons.org/licenses/by/ $4.0 /)$.

\begin{abstract}
We reviewed the evidence on features of central nervous system (CNS) involvement in trichinellosis, systematically searching five databases (to January 2021). We categorized clinical features based on their diagnostic value as warning signs for severe CNS infection (with outcome death) or non-specific signs (outcome improvement). They were suggestive of severe infection if they substantially raised death probability. The review included 87 papers published from 1906 through 2019, with data on 168 patients. Mydriasis, paraparesis, dysphagia, psychomotor seizures, or delirium present a $30-45 \%$ increased death likelihood. The best poor prognosis predictor is mydriasis (positive likelihood ratio 9.08). Slow/absent light reflex, diminished/absent knee reflexes, globally decreased tendon reflexes present a moderate increase (20-25\%) of death risk. Anisocoria, acalculia, or seizures could also indicate an increased death risk. We provided a detailed presentation of clinical and paraclinical signs that alert physicians of a possible neurotrichinellosis, emphasizing signs that might indicate a poor prognosis.
\end{abstract}

Keywords: Trichinella; central nervous system; encephalitis; meningitis; systematic review

\section{Introduction}

Trichinellosis is a parasitic disease caused by the consumption of raw meat infected with larvae of nematode in the genus Trichinella. The first report about the new findings of Trichinella was presented to the zoological society in London in 1835, when Sir Richard Owen, and his student, Sir James Paget, discovered the parasite during an autopsy [1]. Friedrich von Zenker reported the first acute case of human trichinellosis in 1860 [2]. He presented the dissemination mode of the parasites in the host by implicating the consumption of raw, infected pork as the vehicle of transmission. In 1906, Frothingham reported evidence of the central nervous system (CNS) involvement [3]. Later observations revealed the presence of Trichinella in the cerebrospinal fluid (CSF).

Human trichinellosis was reported in $55(27.8 \%)$ countries around the world. Trichinella infection was documented in domestic animals, mainly in pigs, in 43 countries, and the wildlife of 66 countries [4]. A systematic review, including data between 1986 and 2009, reported an estimated global incidence rate of 469.2 to 985.3 cases per billion persons per year. The global mortality rate was $0.300-0.828$ per billion persons per year [5].

The global distribution of Trichinella infection mirrors the geographical distribution of parasites in domestic animals (i.e., pig, horse, dog) and wild animals (i.e., boars, bear, badger, cougar, jackal, walrus, lizard and turtle), the dietary habits (i.e., eating raw meat), and the social and economic development of the countries [6,7]. After 1990, the socioeconomic changes in some Eastern European countries and Argentina, determined the reemergence 
of Trichinella infections in these areas. Nonetheless, in the last years, there was a significant decrease of the number of cases reported in the European Union countries, the United States, Canada and China [8]. Despite a general reduction of the number of cases with Trichinella infection, which is mainly due to the development of systematic regulations regarding the domestic animals (pigs), there has been an increase of the number of Trichinellosis cases due to the consumption of wild animals [7]. In the last decades, important Trichinella outbreaks were reported in South East Asia countries (e.g., Cambodia, Thailand, Vietnam) and South America (e.g., Argentina) [6]. In Africa, there is a low prevalence of human Trichinellosis, possibly due to the dietary and religious habits [4]. However, despite the religious laws forbidding the consumption of pork, Trichinellosis was also documented in Muslim countries such as Turkey [4].

After ingestion, under the influence of gastric secretions, the Trichinella larvae are released in the stomach and develop in the adult stage inside the enterocytes of small intestine. The newborn larvae are released into circulation, spreading through the tissues and organs. Trichinella spp. has an intracellular localization only in two different tissues, specifically, in enterocytes and skeletal muscle cells. It has a unique ability to transform the infected muscle cell and create a new type of cell in the host body, the so-called nurse cell [9]. From this place, the parasite induces the formation of muscle larvae excretory-secretory products (ES L1). The invasion of the host generates a complex immune response, which is better characterized by humoral rather than cellular responses (hence the importance of humoral response for diagnostic purposes) [10]. During the intestinal phase, the immune response includes both Th1 and Th2 responses. Initially, it induces a Th1 responses, followed by a dominant Th2 type of response. This later type of immune response is characterized by the production of high levels of cytokines IL-4, IL-5, IL-9, IL-10, IL-13, immunoglobulin E (IgE), and the mobilization of eosinophils, basophils, and mast cells [11]. The existence of Treg cells further characterizes the muscle phase. The chronic stimulation through ES L1 released during the muscle phase of Trichinella infection activates regulatory network elements. Immune events induced by Th2 and Treg cell types modulate the immune response of the host [11].

The Trichinella infection is characterized by peripheral blood and tissue eosinophilia and an increased total IgE levels, both being a consequence of Th2 activation. Eosinophilopoiesis begins in the bone marrow, followed by the migration of eosinophils through the circulatory system, infiltration of tissues with eosinophils at the inflammatory foci and, finally, degranulation, and cell death [12]. However, the protective role of eosinophiles against Trichinella remains under debate. Furthermore, when the number of eosinophils is increased, they can be toxic to host tissues.

The Trichinella antigens stimulate dendritic cells and macrophages to interact with T cells. Activated T cells produce cytokines, including granulocyte-macrophage colonystimulating factor (GM-CSF), IL-3 and IL-5. They will determine the proliferation and differentiation of precursors into eosinophils. The migration of the eosinophils from the bone marrow to the vessels is controlled mainly by IL-5. The Trichinella antigens might attract and affect eosinophils directly to interact with $\mathrm{T}$ cells. In addition, the alternatively activated macrophages (AAMs) also attract eosinophils through chitinase-like molecule (Ym1) and arginase 1 (Arg1). In addition, eosinophils are attracted by Galectin 9 (Gal-9), eotaxin-1, and eotaxin-2. The eosinophils around Trichinella in the tissues produce cytokines, cytotoxic secretory products, growth factors, lipid mediators, and neuro-mediators. These molecules were reported to play a role in larval killing, tissue injury, or tissue repair, together with various cells. The involvement of eosinophils in worm expulsion from the gut is still uncertain. Nonetheless, the increase of activated eosinophils is responsible for damage to the vascular walls probably because of the release of the major basic protein, which is elevated in patients with eosinophilia. Additionally, it explains tissue damage in the CNS and other tissues [12].

The clinical picture of Trichinella infection is heterogeneous, varying from asymptomatic to fatal, depending on the number and sites of larvae. The symptoms parallel the 
parasite cycle and the responses of the host. The first infection stage consists of non-specific gastroenteritis, occurring two to seven days after ingestion of infected food. The larva migration and invasion determine the characteristic clinical signs and symptoms of Trichinella infection. Larvae and their products cause a diffuse inflammatory reaction, with fever, headache, rash, focal edema, local inflammation, leukocytosis, and eosinophilia. The most affected muscles are the extraocular muscles, masseters, diaphragm, intercostals, deltoids, tongue, larynx, and neck muscles. In severe cases, diffuse and severe muscle involvement manifests with myalgia, especially of the diaphragm, calves, and forearms. Additionally, a characteristic finding is increased muscle consistency, with weakness [1].

The most severe complications are related to the CNS, heart, and lungs [13]. The CNS involvement was reported in $10-20 \%$ of patients and is usually associated with severe Trichinella infection. The reports on mortality vary between $8 \%$ [14] to $46 \%$ [15]. However, with the treatment with corticosteroids and benzimidazoles (e.g., mebendazole and albendazole), the number of fatal outcomes has decreased.

The clinical manifestations of CNS trichinellosis comprise diffuse encephalopathy and focal neurologic deficits. Cerebral invasion occurs during the second week, the larval migratory stage. The patients present with varying degrees of meningoencephalitis manifested by non-focal clinical signs. Focal CNS lesions occur during the third week, the encystment stage. The clinical signs often overlap with previous meningo-encephalitic symptoms. Only rarely are they the sole manifestation and include motor deficits (e.g., hemiparesis), cranial nerve deficits, cerebellar signs, aphasia, and seizures [13]. Additionally, patients may present occlusion of cerebral venous sinus, causing venous infarction or intracerebral hemorrhage [16]. Patients with focal brain damage may present significant diagnostic challenges, mainly if they are first seen with a focal cerebral picture.

The meningeal form frequently causes minimal mental and focal signs, while in the parenchymal form, patients present marked mental and focal signs with minimal meningeal involvement [13].

The Centers for Disease Control (CDC) case definition for trichinellosis comprises: (1) Trichinella-positive muscle biopsy or positive serologic test for trichinellosis in a patient with a clinical syndrome compatible with trichinellosis (including eosinophilia, fever, myalgia, and periorbital edema) or (2) in an outbreak, at least one person must meet criteria 1, with associated cases defined by a positive serologic test for trichinellosis or clinical symptoms compatible with trichinellosis (including eosinophilia, fever, myalgia, and periorbital edema) in individuals who shared the epidemiologically implicated meal or have consumed the implicated meat product [17].

The case definition for trichinellosis at the European Center for Disease Control states, "at least three of the following six: fever, muscle soreness and pain, gastrointestinal symptoms, facial edema, eosinophilia, and subconjunctival, subungual, and retinal hemorrhages" $[10,17]$.

The differential diagnostic difficulties rarely arise in cases of "typical" acute trichinellosis. However, the cases with CNS involvement may represent a diagnostic challenge, especially in the lack of eosinophilia. In addition, the presentations of CNS infection are myriad, and the diagnosis can be elusive [18].

The drugs of choice in Trichinellosis are anthelmintics (albendazole or mebendazole). They should be given before the initiation of corticosteroids to prevent the effect of delayed expulsion of adult worms from the intestine. Their efficacity depends on the time delay between infection and the beginning of treatment, and it is likely dose-dependent [19]. Although no valid controlled studies have been performed, corticosteroids are frequently used to treat allergic manifestations, which occur at the beginning of the parenteral phase [10]. The corticotherapy is strongly recommended to suppress the vascular and muscle damage induced by eosinophil degranulation products [20]. In severe cases, corticosteroids were reported to reduce the course of the illness [21]; after their implementation, the number of fatal cases with neurological involvement has decreased significantly [19]. In addition, the neurological complications occurring in the early period of the illness were reported to be 
successfully treated with corticosteroids. Still, when these complications appear after one month, they can cause permanent sequelae [19].

In addition, practical recommendations have been published for severe and moderately severe diseases [10].

In the latest years, experts have developed risk-based approaches to control the presence of parasites in meat, requiring the re-evaluation of traditional practices and the assessment of regulatory and industry resources. In 2020, the Food and Agriculture Organization of the United Nations (FAO) and World Health Organization (WHO) published a report that provides spreadsheet models to get quantitative information needed by public health officials when evaluating different post-mortem hygiene programs for Trichinella spp. in meat [22]. These models enable the development of risk scenarios to assess the effect of changes to digestion testing and meat inspection on the risk of human Trichinellosis [22]. Applying the latest risk-based approach recommendations requires a re-evaluation of traditional practices and assessing regulatory and industry resources proportionate to risks. In addition, the link between control measures pre-and post-harvest along the food chain and public health outcomes will help risk managers locate the source of the infection at the farm, abattoir, processor, and consumer level for food safety interventions, according to the publication [22]. In addition, there are international recommendations for quality assurance in digestion testing programs for Trichinella [23]. Additionally, many countries have specific regulations for the inspection and control of the parasite, and there are different treatment methods to inactivate Trichinella larvae in meat, including cooking, irradiation, and freezing for some genotypes.

The present research aimed to systematically review and summarize the existing evidence on the CNS complications of Trichinellosis infection, described in case reports and case series. Although a case report provides only a descriptive result, systematic reviews of multiple cases allow narrative or quantitative synthesis, pattern recognition, and identification of unrecognized or rare associations. Furthermore, it can generate hypotheses for subsequent studies and advance medical knowledge.

\section{Materials and Methods}

The present systematic review was performed following the guidelines of the Preferred Reporting Items for Systematic Reviews and Meta-Analysis (PRISMA) [24] and the recent recommendations on the synthesis of case series and case reports [25].

We performed a computerized bibliographic search from inception to January 2021 on the following databases: MEDLINE/PubMed, EMBASE, Scopus, Web of Sciences, and Latin American and Caribbean Health Sciences Literature (LILACS). In addition, we performed a complementary manual search by checking reference lists of all relevant research papers to identify possible additional studies. The following keywords were used: "trichinosis" AND "brain disease" [MeSH], "trichinosis" AND "central nervous system disease" [MeSH], "trichinella spiralis" AND "brain disease" [MeSH], "trichinella spiralis" AND "central nervous system disease" [MeSH], and "neurotrichinosis". These search terms were for PubMed. Searches in other data sources used similar versions of these terms, appropriate for each database. We did not utilize search filters (collection of terms to reduce the number needed to be screened) because we aimed to generate a comprehensive list of papers suitable for answering the research question. Additionally, we did not apply any language restrictions to our search.

Two authors reviewed the title, abstract, and full text (when needed) of all retrieved research papers and assessed whether the study met the inclusion criteria. Disagreements were solved through discussion.

To perform a systematic review of the CNS involvement in trichinellosis, we selected all the studies reporting children or adults diagnosed with trichinellosis and meningeal or brain damage signs. The main types of eligible studies were case reports and case series reports. 
We excluded studies with no data on at least one aspect of CNS involvement, including clinical signs, CSF study, autopsy or biopsy, or neuroimaging. Additionally, we excluded studies in languages other than English and Spanish.

Data were extracted to a proforma template that two authors initially piloted on a set of five randomly selected case reports and adjusted as necessary. Data were extracted by one reviewer and verified by a second reviewer.

Descriptive statistics of patient clinical and paraclinical variables were estimated. Case report data were grouped by the outcome (improvement or death).

In addition, we reconstructed two-by-two tables based on clinical information in the case reports where an outcome was available. We calculated the likelihood ratios for a positive result $(\mathrm{LR}+)$, representing the probability that a patient with a specific clinical sign could die, as well as the likelihood ratios for negative results $(\mathrm{LR}-)$, referring to the probability that an individual presenting a specific clinical sign could present a less severe CNS infection, with improvement. For statistical calculations, we used the RevMan program.

The clinical features were categorized based on their diagnostic value as either warning signs for severe CNS infection (with outcome death) or non-specific signs for severe infection (with outcome improvement). Clinical features were considered suggestive for severe infection if, when positive, they substantially raised the probability of death (i.e., $\mathrm{LR}+$ of more than 5.0).

The $\mathrm{LR}+$ may range from 0 to infinity. The larger $\mathrm{LR}+$, the more informative is the test. Findings with LR+ greater than 1 indicate an increased odd of having a particular condition in a patient with a positive result. The bigger the number, the more convincingly the finding suggests the presence of disease. If LR+ lies between 0 and 1, it argues against the diagnostic value of the test [26]. When diagnostic test accuracy results are around 1, it lacks diagnostic value [26]. A simple estimative method, independent of pretest probabilities and avoiding complex calculations, enables the clinician to make a bedside estimation: an LR+ of 2 causes a small change in disease likelihood, increasing the probability of the disease by $15 \%$, one of 5 increases it 30\%, determining a moderate change, and one of 10 increases it $45 \%$, determining a large change in disease likelihood [26]. At the same time, the LR - indicates the odds of having a disease in patients with negative test results. If the LR - is smaller than 1, then the post-test probability of the disease decreases. The smaller the LR - the more informative is the test [26].

\section{Results}

Our search resulted in 4011 records. From a total of 160 unique studies identified using the search strategy and assessed in full-text, we included in the present review 87 papers [3,13-16,18,20,27-106]. The PRISMA diagram describing the selection process of studies is detailed in Figure 1.

Seventy-three studies were excluded for the following reasons: no full text was available $(n=13)$; the paper was in other languages $(n=13)$; the patients did not present CNS involvement $(n=24)$; the article was a review $(n=9)$ or a commentary $(n=2)$; no data was available $(n=4)$; the patients presented chronic disease $(n=3)$, and the disease was not trichinellosis $(n=5)$. Table S1.

The characteristics of the included case reports are summarized in Supplementary

The present review included 168 cases of patients with meningeal or brain disease due to Trichinella infection. Acute cerebral sinus thrombosis was reported in five papers $[16,41,83,92,104]$. The rest were reports of meningitis or neurotrichinellosis. The year of publication ranged from 1906 through 2019. 


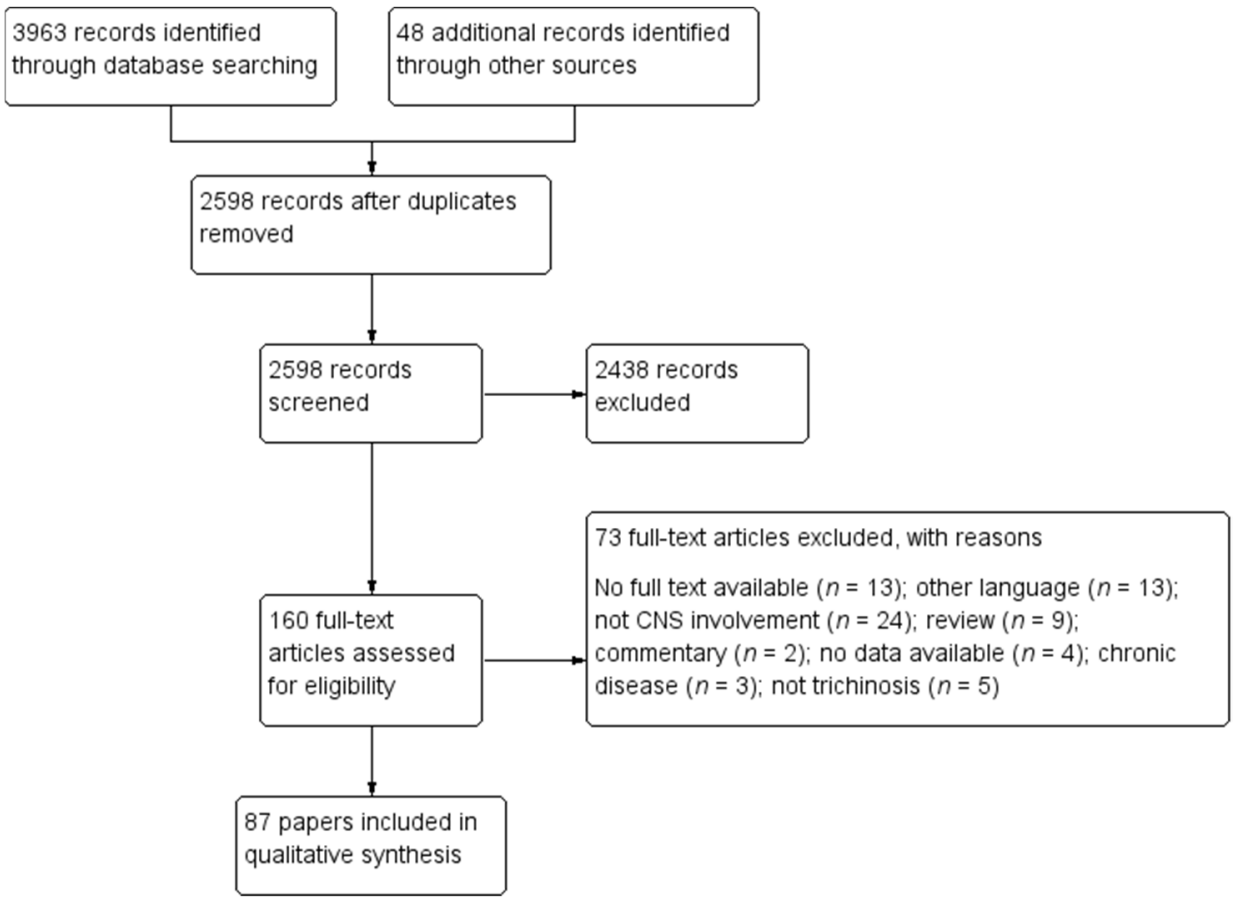

Figure 1. Study selection flowchart.

\subsection{Clinical Findings}

The clinical picture was presented in 162 cases (Table 1, Supplementary Table S1).

The most frequent clinical symptoms were headache (24.69\% of patients), confusion $(14.2 \%)$, disorientation $(11,73 \%)$, delirium $(9.87 \%)$, and meningeal signs including positive Kerning sign (14.8\%) and neck stiffness (13.58\%). Central motor deficits were also frequent (19.14\% hemiparesis, $10.49 \%$ tetraparesis, $8.02 \%$ monoparesis, and $1.23 \%$ paraparesis). They are associated with pathological tendon reflexes (brisk or, on the contrary, diminished) and positive Babinski sign (unilateral in $8.02 \%$ of cases, bilateral in $9.88 \%$ of cases, doubtful in $0.62 \%$ of patients). Sensitive impairment was rare, with hemihypoesthesia in $3.70 \%$ of patients and subjective symptoms (e.g., numbness, dysesthesia) in $3.70 \%$ of cases. Cerebellar impairments were reported in $9.25 \%$ of patients. Cranial nerves were also affected, with third nerve palsy $(4.94 \%)$, sixth nerve palsy $(5.56 \%)$, peripheral facial palsy $(0.62 \%)$, dysphagia $(1.23 \%)$, and dysarthria $(0.62 \%)$. Pupillary abnormalities consisted of mydriasis $(3.09 \%)$, anisocoria $(3.09 \%)$, and absent or slow light reaction $(4.94 \%)$.

Hemiballismus, an involuntary movement disorder, was reported in one case $(0.62 \%)$. Epileptic seizures were present in some rare instances (generalized seizures $2.46 \%$, jacksonian seizures $1.85 \%$, petit mal $1.23 \%$, and psychomotor seizures $1.85 \%$ ).

Cognitive problems included memory impairments, affecting mainly the recent memory $(10.49 \%)$, aphasia $(6.79 \%)$, acalculia $(1.85 \%)$, apraxia $(0.62 \%)$, and anosognosia $(0.62 \%)$. Behavioral disturbances consisted of apathy $(4.94 \%)$, anxiety (1.23\%), insomnia $(2.47 \%)$, agitation $(3.08 \%)$, and irritability $(2.47 \%)$. Psychiatric disturbances (e.g., psychosis, bizarre mental attitude, hallucinations, paranoid reactions) were present in $12.96 \%$ of patients.

Of the 162 cases, coma was reported in $6.79 \%$, stupor in $2.47 \%$, lethargy in $6.17 \%$, somnolence in $6.17 \%$, and drowsiness in $6.17 \%$.

A detailed presentation of all the reported symptoms is presented in Table 1. 
Table 1. Clinical symptoms and signs of included cases.

\begin{tabular}{|c|c|c|c|}
\hline \multicolumn{2}{|c|}{ Clinical Sign/Symptom } & Number of Cases ( $\%$ of Total; $N=162$ ) & Deaths \\
\hline \multicolumn{2}{|c|}{ Headache } & $40(24.69 \%)$ & 7 \\
\hline \multicolumn{2}{|c|}{ Neck stiffness } & $22(13.58 \%)$ & 2 \\
\hline \multicolumn{2}{|c|}{ Kerning sign } & $24(14.8 \%)$ & 16 \\
\hline \multicolumn{2}{|c|}{ Meningeal cry } & $2(1.23 \%)$ & 0 \\
\hline \multicolumn{2}{|c|}{ Confusion } & $23(14.2 \%)$ & 1 \\
\hline \multicolumn{2}{|c|}{ Delirium } & $16(9.87 \%)$ & 7 \\
\hline \multicolumn{2}{|c|}{ Disorientation } & 19 (11.73) & 3 \\
\hline \multicolumn{2}{|c|}{ Agitation } & $5(3.08 \%)$ & 0 \\
\hline \multicolumn{2}{|c|}{ Insomnia } & $4(2.47 \%)$ & 0 \\
\hline \multicolumn{2}{|c|}{ Irritability } & $4(2.47 \%)$ & 1 \\
\hline \multicolumn{2}{|c|}{ Psychiatric symptoms } & $21(12.96 \%)$ & 0 \\
\hline \multicolumn{2}{|c|}{ Mutism } & $1(0.62 \%)$ & 0 \\
\hline \multicolumn{2}{|c|}{ Euphoria } & $2(1.23 \%)$ & 0 \\
\hline \multicolumn{2}{|c|}{ Depression } & $8(4.94 \%)$ & 1 \\
\hline \multicolumn{2}{|c|}{ Anxiety } & $2(1.23 \%)$ & 0 \\
\hline \multicolumn{2}{|c|}{ Apathy } & $8(4.94 \%)$ & 1 \\
\hline \multicolumn{2}{|c|}{ Bradypsychia } & $4(2.47 \%)$ & 0 \\
\hline \multicolumn{2}{|c|}{ Memory impairment (recent memory) } & $17(10.49 \%)$ & 1 \\
\hline \multicolumn{2}{|c|}{ Impaired abstract thinking } & $4(2.47 \%)$ & 0 \\
\hline \multicolumn{2}{|c|}{ Impaired concentration } & $1(0.62 \%)$ & 0 \\
\hline \multicolumn{2}{|c|}{ Anosognosia } & $1(0.62 \%)$ & 0 \\
\hline \multicolumn{2}{|c|}{ Apraxia } & $1(0.62 \%)$ & 0 \\
\hline \multicolumn{2}{|c|}{ Acalculia } & $3(1.85 \%)$ & 1 \\
\hline \multicolumn{2}{|c|}{ Aphasia } & $11(6.79 \%)$ & 3 \\
\hline \multicolumn{2}{|c|}{ Tetraparesis } & $17(10.49 \%)$ & 3 \\
\hline \multicolumn{2}{|c|}{ Hemiparesis } & $31(19.14 \%)$ & 5 \\
\hline \multicolumn{2}{|c|}{ Paraparesis } & $2(1.23 \%)$ & 1 \\
\hline \multicolumn{2}{|c|}{ Monoparesis } & $13(8.02 \%)$ & 1 \\
\hline \multirow{4}{*}{ Brisk tendon reflexes } & Globally & $9(5.56 \%)$ & 1 \\
\hline & On the hemiparesis side & $4(2.47 \%)$ & 0 \\
\hline & Knee & $3(1.85 \%)$ & 0 \\
\hline & Lower limbs & $7(9.87 \%)$ & 0 \\
\hline & & $9(5.56 \%)$ & 0 \\
\hline Ro & & $1(0.62 \%)$ & 0 \\
\hline
\end{tabular}


Table 1. Cont.

\begin{tabular}{|c|c|c|c|}
\hline \multicolumn{2}{|c|}{ Clinical Sign/Symptom } & \multirow{2}{*}{$\frac{\text { Number of Cases (\% of Total; } N=\mathbf{1 6 2})}{11(6.79 \%)}$} & \multirow{2}{*}{$\frac{\text { Deaths }}{4}$} \\
\hline \multirow{5}{*}{ Diminished/absent tendon reflexes } & Globally & & \\
\hline & Lower limbs & $5(3.09 \%)$ & 5 \\
\hline & Knee & $8(4.94 \%)$ & 2 \\
\hline & Ankle & $3(1.85 \%)$ & 0 \\
\hline & Unilateral & $1(0.62 \%)$ & 0 \\
\hline \multirow[t]{3}{*}{ Babinski sign } & Unilateral & $13(8.02 \%)$ & 1 \\
\hline & Bilateral & $16(9.88 \%)$ & 3 \\
\hline & Doubtful & $1(0.62 \%)$ & 0 \\
\hline \multirow[t]{2}{*}{ Sensitive impairment } & Hemihypoesthesia & $6(3.70 \%)$ & 0 \\
\hline & Subjective symptoms & $6(3.70 \%)$ & 0 \\
\hline \multicolumn{2}{|c|}{ Cerebellar signs } & $15(9.25 \%)$ & 0 \\
\hline \multirow{7}{*}{ Cranial nerves } & Third nerve palsy & $8(4.94 \%)$ & 1 \\
\hline & Sixth nerve palsy & $9(5.56 \%)$ & 1 \\
\hline & Peripheral facial palsy & $1(0.62 \%)$ & 0 \\
\hline & Dysphagia & $2(1.23 \%)$ & 0 \\
\hline & Pseudobulbar dysphagia & $2(1.23 \%)$ & 1 \\
\hline & Dysarthria & $1(0.62 \%)$ & 0 \\
\hline & Unspecified & $2(1.23 \%)$ & 1 \\
\hline \multicolumn{2}{|c|}{ Mydriasis } & $5(3.09 \%)$ & 3 \\
\hline \multicolumn{2}{|c|}{ Anisocoria } & $5(3.09 \%)$ & 2 \\
\hline \multicolumn{2}{|c|}{ Absent/slow light reaction } & $8(4.94 \%)$ & 3 \\
\hline \multicolumn{2}{|c|}{ Ocular bobbing } & $1(0.62 \%)$ & 0 \\
\hline \multicolumn{2}{|c|}{ Horner syndrome } & $1(0.62 \%)$ & 0 \\
\hline \multicolumn{2}{|c|}{ Visual impairment } & $10(6.17 \%)$ & 0 \\
\hline \multicolumn{2}{|c|}{ Hemiballismus } & $1(0.62 \%)$ & 0 \\
\hline \multirow{5}{*}{ Seizures } & Generalized & $4(2.46 \%)$ & 1 \\
\hline & Jacksonian type & $3(1.85 \%)$ & 1 \\
\hline & Petit mal & $2(1.23 \%)$ & 0 \\
\hline & Psychomotor & $3(1.85 \%)$ & 1 \\
\hline & Unspecified & $2(1.23 \%)$ & 1 \\
\hline \multicolumn{2}{|c|}{ Coma } & $11(6.79 \%)$ & 3 \\
\hline \multicolumn{2}{|c|}{ Stupor } & $4(2.47 \%)$ & 1 \\
\hline \multicolumn{2}{|c|}{ Somnolence } & $10(6.17 \%)$ & 0 \\
\hline \multicolumn{2}{|c|}{ Lethargy } & $10(6.17 \%)$ & 1 \\
\hline \multicolumn{2}{|c|}{ Obnubilation } & $1(0.62 \%)$ & 0 \\
\hline \multicolumn{2}{|c|}{ Drowsiness } & $10(6.17 \%)$ & 3 \\
\hline \multicolumn{2}{|c|}{ Dizziness } & $5(3.09 \%)$ & 0 \\
\hline \multicolumn{2}{|c|}{ Frontal signs (unspecified) } & $3(1.85 \%)$ & 0 \\
\hline \multicolumn{2}{|c|}{ Encephalitic signs (unspecified) } & $2(1.23 \%)$ & 0 \\
\hline
\end{tabular}




\subsection{Clinical Findings in Patients with Reported Outcome}

The outcome was published in 124 cases: 20 patients died, and 104 improved.

Among 20 patients who died, the clinical picture was presented in 17. The most frequent symptoms consisted of headache $(41.17 \%)$, disorientation $(41.17 \%)$, followed by motor deficits (hemiparesis $23.53 \%$, tetraparesis $17.65 \%$, and paraparesis $5.88 \%$ ), diminished or absent tendon reflexes (globally $23.53 \%$, or knee reflexes $11.76 \%$ ), Kerning sign (17.56\%), pupillary abnormalities (mydriasis $17.6 \%$, anisocoria $11.76 \%$, and slow or absent light reflex $17.65 \%)$, aphasia $(17.65 \%)$, and drowsiness $(17.65 \%)$. A complete list with the symptoms reported in patients who died is presented in Table 2.

Table 2. Clinical signs and symptoms of cases with reported outcome.

\begin{tabular}{|c|c|c|c|}
\hline \multicolumn{2}{|c|}{ Clinical Sign/Symptom } & $\begin{array}{l}\text { Number of Cases with Outcome } \\
\text { Death (\% of Total; } N=17)\end{array}$ & $\begin{array}{l}\text { Number of Cases with Outcome } \\
\text { Improvement }(N=103)\end{array}$ \\
\hline \multicolumn{2}{|c|}{ Headache } & $7(41.17 \%)$ & 33 \\
\hline \multicolumn{2}{|c|}{ Neck stiffness } & $2(11.76 \%)$ & 20 \\
\hline \multicolumn{2}{|c|}{ Kerning sign } & $2(17.65 \%)$ & 8 \\
\hline \multicolumn{2}{|c|}{ Confusion } & $1(5.88 \%)$ & 22 \\
\hline \multicolumn{2}{|c|}{ Delirium } & $7(41.17 \%)$ & 8 \\
\hline \multicolumn{2}{|c|}{ Disorientation } & $3(17.65 \%)$ & 17 \\
\hline \multicolumn{2}{|c|}{ Depression } & $1(5.88 \%)$ & 7 \\
\hline \multicolumn{2}{|c|}{ Apathy } & $1(5.88 \%)$ & 7 \\
\hline \multicolumn{2}{|c|}{ Memory impairment (recent memory) } & $1(5.88 \%)$ & 10 \\
\hline \multicolumn{2}{|c|}{ Acalculia } & $1(5.88 \%)$ & 2 \\
\hline \multicolumn{2}{|c|}{ Aphasia } & $3(17.65 \%)$ & 8 \\
\hline \multicolumn{2}{|c|}{ Tetraparesis } & $3(17.65 \%)$ & 14 \\
\hline \multicolumn{2}{|c|}{ Hemiparesis } & $6(35.29 \%)$ & 22 \\
\hline \multicolumn{2}{|c|}{ Paraparesis } & $1(5.88 \%)$ & 1 \\
\hline \multicolumn{2}{|c|}{ Monoparesis } & $1(5.88 \%)$ & 12 \\
\hline Brisk tendon reflexes & Globally & $1(5.88 \%)$ & 5 \\
\hline \multirow{2}{*}{$\begin{array}{l}\text { Diminished/absent tendon } \\
\text { reflexes }\end{array}$} & Globally & $4(23.53 \%)$ & 7 \\
\hline & Knee & $2(11.76 \%)$ & 4 \\
\hline \multicolumn{2}{|c|}{ Present tendon reflexes } & $1(5.88 \%)$ & 1 \\
\hline \multirow{2}{*}{ Babinski sign } & Unilateral & $1(5.88 \%)$ & 11 \\
\hline & Bilateral & $3(17.65 \%)$ & 14 \\
\hline \multirow{3}{*}{ Cranial nerves } & Third nerve palsy & $1(5.88 \%)$ & 5 \\
\hline & Sixth nerve palsy & $1(5.88 \%)$ & 8 \\
\hline & Dysphagia & $1(5.88 \%)$ & 1 \\
\hline \multicolumn{2}{|c|}{ Mydriasis } & $3(17.65 \%)$ & 2 \\
\hline \multicolumn{2}{|c|}{ Anisocoria } & $2(11.76 \%)$ & 3 \\
\hline \multicolumn{2}{|c|}{ Absent/slow light reaction } & $3(17.65 \%)$ & 5 \\
\hline \multirow{4}{*}{ Seizures } & Generalized & $1(5.88 \%)$ & 2 \\
\hline & Jacksonian type & $1(5.88 \%)$ & 3 \\
\hline & Psychomotor & $1(5.88 \%)$ & 1 \\
\hline & Unspecified & $1(5.88 \%)$ & 0 \\
\hline \multicolumn{2}{|c|}{ Coma } & $3(17.65 \%)$ & 8 \\
\hline \multicolumn{2}{|c|}{ Stupor } & $1(5.88 \%)$ & 3 \\
\hline \multicolumn{2}{|c|}{ Lethargy } & $1(5.88 \%)$ & 8 \\
\hline \multicolumn{2}{|c|}{ Drowsiness } & $3(17.65 \%)$ & 7 \\
\hline
\end{tabular}




\subsection{Cerebrospinal Fluid Analysis}

The CSF findings were reported in 107 patients (see Table 3).

Table 3. Cerebrospinal fluid (CSF) findings of included cases.

\begin{tabular}{|c|c|c|}
\hline \multicolumn{2}{|c|}{ CSF Parameter } & \multirow{2}{*}{$\frac{\text { No. of Cases (\% of Total; } N=107)}{11(10.28 \%)}$} \\
\hline \multirow{2}{*}{ Pressure } & increased & \\
\hline & decreased & $3(2.80 \%)$ \\
\hline \multirow{3}{*}{ Cells } & Lymphocytes & $16(14.95)$ \\
\hline & Erythrocytes & $4(3.74 \%)$ \\
\hline & Unspecified & $3(2.80)$ \\
\hline \multirow{2}{*}{ Proteins } & Increased & $16(14.95 \%)$ \\
\hline & Decreased & $6(5.60 \%)$ \\
\hline \multirow{2}{*}{ Glucose } & Increased & $5(4.67 \%)$ \\
\hline & Decreased & $1(0.93 \%)$ \\
\hline \multicolumn{2}{|c|}{ Positive for Trichinella sp. larvae } & $20(18.69 \%)$ \\
\hline \multicolumn{2}{|c|}{ Anti-trichinella antibodies } & $1(0.93 \%)$ \\
\hline \multicolumn{2}{|c|}{ Normal findings } & $44(41.12 \%)$ \\
\hline
\end{tabular}

Almost half of the patients presented normal findings (41.12\%). The pressure was reported increased by $10.28 \%$ of cases and decreased in a few cases $(2.80 \%)$. The cells found in the CSF were lymphocytes $(14.95 \%)$ or erythrocytes $(3.74 \%)$. Proteins were increased in $14.95 \%$ of cases and decreased in $5.60 \%$ of patients. Glucose level was rarely modified (increased-4.67\%, and decreased-0.93\%). Authors found a CSF positive for Trichinella sp. larvae in $18.69 \%$ of patients. Anti-Trichinella antibodies were detected in the CFS of one patient.

Among the 20 patients who died, the CSF analysis was reported in 14. Four reports comprised only of data on the presence of Trichinella sp. larvae, without any data on the other CSF parameters. Among the remaining ten patients, four presented completely normal CSF findings. One patient presented increased pressure, one had decreased CSF pressure, and eight presented normal pressure. Lymphocytes were found in two cases; the other two patients were reported to have CSF cells, but their type was not specified. Two patients presented no cells in the CSF. The protein level was increased in three cases and normal in seven cases. Eight patients presented normal glucose levels, one an increased level, and one a decreased level. In total, the presence of Trichinella sp. larvae was assessed in six cases, with three positive and three negative findings.

\subsection{Blood Eosinophils}

The blood level of eosinophils was reported in 107 patients. In the group with clinical improvement, consisting of 96 patients, the majority (89.58\%) presented eosinophilia. In the group of the patients who died, data on eosinophils count was provided in 11 patients. Eosinophilia was present in $45.45 \%$ of cases, the rest of $54.55 \%$ being without increased eosinophils in the blood.

\subsection{Autopsy and Biopsy Findings}

Autopsy data was published in 14 patients, the last report being in 1993 [20]. The findings consisted of diffuse inflammatory changes, typical for acute encephalitis [36], areas of cellular infiltration comprised of endothelial cells, glial cells, and lymphocytes [3,36,42]. Some authors also reported mild brain hemorrhages without marked cellular reaction [3,80], but others noted the absence of hemorrhages [36]. In addition, autopsy findings included nodules distributed through the hematogenous elements, harboring Trichinella [36,46]. Other authors 
also reported the presence of Trichinella larvae outside the vessels [3,30,41,42,71]. Nonetheless, other authors report the absence of Trichinella in the brain $[16,20,48]$. The nodules were found mainly in the subcortical white matter [46]. Etat criblé, with numerous round and oval cavities, was present in some patients (Supplemental material S1) [20,32,46].

Other autopsy findings consisted of congestion and hyperemia of the brain vessels [36,42,43,46], perivascular infiltrates [46], and meningeal congestion [32,36,42,43].

One paper, published in 2007, reported data on brain biopsy [98]. The authors described the presence of active vasculitic changes, with focal necrosis of the vessels and deposits of eosinophils [98].

\subsection{Neuroimaging Findings}

Neuroimaging was performed in 49 patients. Eight patients had a skull radiograph. One revealed a brain calcification [38], and the rest were normal. CT scans were performed in 27 cases. Five patients presented a normal CT scan. In 22 cases, the CT revealed some abnormalities, consisting mainly of hypodense lesions, situated with predilection in the white matter. Some authors reported lesions with nodular enhancement [89] or non-specific enhancement $[83,87]$. One author found cerebral hemorrhage in a patient who presented on autopsy cerebral sinus thrombosis [16]. Calcification rings were described in 1 patient [89]. Sinus thrombosis was present in one patient [104].

A brain MRI was reported in 14 patients. Most authors reported the presence of high signal lesions in the T2 weighted sequences, located in the white matter $[20,87,94,97,98,101,102,105,106]$. In T1 sequences, patients presented a slight signal increase [97] or hypointense lesions [101]. The DWI sequences revealed a restricted diffusion, suggesting ischemia [97,101]. In apparent diffusion coefficient (ADC) sequences, the lesions were hypointense [98]. Interestingly, some papers reported that the lesions were situated in the border zones of distal fields of major cerebral arteries $[97,98,105,106]$. Although most of the lesions were reported to be in the white brain matter, the MRI scans also detected lesions at the white matter and grey matter interface, in the cortex [102], cerebellum [98,101,105,106], and thalamus [106]. Furthermore, McDonald et al. [101] observed that the lesions were distributed mainly in the frontal and parietal lobes, with fewer lesions in the temporal and occipital lobes and cerebellum.

Some of the lesions found on MRI presented rim enhancement [101], or peripheral enhancement, indicating a breakdown of the blood-brain barrier [98], focal nodular enhancement [94], or focal gyriform enhancement [94].

In one case of cerebral sinus thrombosis, the patient presented on MRI a hemorrhagic infarct [92].

Among the patients with neuroimaging data, only three presented a severe outcome (death): one had cortical sinus and venous thrombosis, with a secondary hemorrhage [16], one presented on the CT scan multiple unenhanced hypointensities located bilaterally in the white matter [20], and one had a hemorrhagic infarct secondary to the superior sagittal and lateral sinus thrombosis [92]. Nonetheless, due to the low number of neuroimaging data in severe cases, it was impossible to ascertain if any neuroimaging features could indicate a severe prognosis.

\subsection{Statistical Analysis}

The probability of a severe CNS infection (with outcome death), based on LR+ of clinical neurological features, was calculated based on data from 120 patients. Among them, 17 died, and 103 improved. The highest LR+ was obtained for mydriasis (9.08), paraparesis (6.05), dysphagia (6.05), psychomotor seizures (6.05), and delirium (5.30). A moderate increase of risk of death was indicated by the presence of clinical signs with LR+ between 3 and 5: acalculia (3.02), diminished or absent knee reflex (3.02), globally decreased tendon reflexes (3.46), anisocoria (4.03), slow or absent light reflex (4.03), and seizures (4.03). The lowest LR+ was found for confusion (0.27), monoparesis (0.50), unilateral Babinski sign $(0.55)$, neck stiffness $(0.60)$, recent memory impairments $(0.60)$, lethargy $(0.75)$, sixth cranial 
nerve palsy (0.75), depression (0.86), and apathy (0.86). The detailed presentation of the LR is presented in Table 4.

Table 4. Data on the probability of a severe CNS infection (with outcome death) based on likelihood ratios of clinical neurologic features.

\begin{tabular}{|c|c|c|c|c|c|c|c|}
\hline \multicolumn{2}{|l|}{ Symptom } & TP & FP & FN & TN & LR+ & LR - \\
\hline \multicolumn{2}{|l|}{ Headache } & 7 & 33 & 10 & 70 & 1.28 & 0.86 \\
\hline \multicolumn{2}{|l|}{ Neck stiffness } & 2 & 20 & 15 & 83 & 0.60 & 1.09 \\
\hline \multicolumn{2}{|l|}{ Kerning sign } & 2 & 8 & 15 & 95 & 1.51 & 0.95 \\
\hline \multicolumn{2}{|l|}{ Confusion } & 1 & 22 & 16 & 81 & 0.27 & 1.19 \\
\hline \multicolumn{2}{|l|}{ Delirium } & 7 & 8 & 10 & 95 & 5.30 & 0.63 \\
\hline \multicolumn{2}{|l|}{ Disorientation } & 3 & 17 & 14 & 86 & 1.06 & 0.98 \\
\hline \multicolumn{2}{|l|}{ Depression } & 1 & 7 & 16 & 96 & 0.86 & 1.00 \\
\hline \multicolumn{2}{|l|}{ Apathy } & 1 & 7 & 16 & 96 & 0.86 & 1.00 \\
\hline \multicolumn{2}{|l|}{ Memory impairment } & 1 & 10 & 16 & 93 & 0.60 & 1.04 \\
\hline \multicolumn{2}{|l|}{ Acalculia } & 1 & 2 & 16 & 101 & 3.02 & 0.95 \\
\hline \multicolumn{2}{|l|}{ Aphasia } & 3 & 8 & 14 & 95 & 2.27 & 0.89 \\
\hline \multicolumn{2}{|l|}{ Tetraparesis } & 3 & 14 & 14 & 89 & 1.29 & 0.95 \\
\hline \multicolumn{2}{|l|}{ Hemiparesis } & 6 & 22 & 11 & 81 & 1.65 & 0.82 \\
\hline \multicolumn{2}{|l|}{ Paraparesis } & 1 & 1 & 16 & 102 & 6.05 & 0.95 \\
\hline \multicolumn{2}{|l|}{ Monoparesis } & 1 & 12 & 16 & 91 & 0.50 & 1.06 \\
\hline \multicolumn{2}{|l|}{ Brisk tendon reflexes (globally) } & 1 & 5 & 16 & 98 & 1.21 & 0.98 \\
\hline \multirow{2}{*}{ Diminished tendon reflexes } & Globally & 4 & 7 & 13 & 96 & 3.46 & 0.82 \\
\hline & Knee & 2 & 4 & 15 & 99 & 3.02 & 0.91 \\
\hline \multirow{2}{*}{ Babinski sign } & Unilateral & 1 & 11 & 16 & 92 & 0.55 & 1.05 \\
\hline & Bilateral & 3 & 14 & 14 & 89 & 1.29 & 0.95 \\
\hline \multicolumn{2}{|l|}{ Third cranial nerve palsy } & 1 & 5 & 16 & 98 & 1.21 & 0.98 \\
\hline \multicolumn{2}{|l|}{ Sixth cranial nerve palsy } & 1 & 8 & 16 & 95 & 0.75 & 1.02 \\
\hline \multicolumn{2}{|l|}{ Dysphagia } & 1 & 1 & 16 & 102 & 6.05 & 0.95 \\
\hline \multicolumn{2}{|l|}{ Mydriasis } & 3 & 2 & 14 & 101 & 9.08 & 0.83 \\
\hline \multicolumn{2}{|l|}{ Anisocoria } & 2 & 3 & 15 & 100 & 4.03 & 0.90 \\
\hline \multicolumn{2}{|l|}{ Absent/slow light reflex } & 3 & 5 & 14 & 98 & 3.63 & 0.86 \\
\hline \multicolumn{2}{|l|}{ Jacksonian seizures } & 1 & 3 & 16 & 100 & 2.01 & 0.96 \\
\hline \multicolumn{2}{|l|}{ Psychomotor seizures } & 1 & 1 & 16 & 102 & 6.05 & 0.95 \\
\hline \multicolumn{2}{|l|}{ Any type of seizures } & 4 & 6 & 13 & 97 & 4.03 & 0.81 \\
\hline Coma & & 3 & 8 & 14 & 96 & 2.27 & 0.89 \\
\hline Stupor & & 1 & 3 & 16 & 100 & 2.01 & 0.96 \\
\hline Lethargy & & 1 & 8 & 16 & 95 & 0.75 & 1.02 \\
\hline Drowsiness & & 3 & 7 & 14 & 96 & 2.59 & 0.88 \\
\hline
\end{tabular}

Abbreviations: TP-true positive; FP—false positive; FN—false negative; TN—true negative; LR+—positive likelihood ratio; LR-negative likelihood ratio.

\section{Discussion}

The present systematic review enabled us to make several key observations. 
The most frequent clinical features of the CNS involvement in Trichinella infection consist of some non-specific meningo-encephalitic findings, such as headaches, confusion, spatial and temporal disorientation, and meningeal signs, including neck stiffness and Kerning signs. Additionally, patients may present focal brain damage, indicated mainly by motor deficits, most frequently hemiparesis. Tendon reflexes might be brisk or diminished, and the Babinski sign is also present in almost one-quarter of the patients. Cerebellar and cranial nerve involvement is relatively rare, and so are seizures.

Psychiatric and behavioral disturbances are not very frequent. Cognitive impairments consist mainly of deficits in recent memory $[20,46,61,62,76,79,103]$, resembling Korsakoff syndrome and aphasia [20,34,41,70,76,94,99,101,105].

Interestingly, in patients who died, the headache, neck stiffness, and positive Kerning sign rates were quite similar to those with a favorable outcome. However, delirium was present in almost half of the deceased cases (41.17\%), compared to $9.87 \%$ in the group of all patients. Additionally, the tendon reflexes were diminished in almost half of the patients with unfavorable outcome. Among 24 patients with decreased knee tendon reflexes, 11 died. Mydriasis and absent or slow light reflex were reported in a higher percentage of patients who died than patients with improvement. (17.65\% mydriasis and $17.5 \%$ slow light reflex vs. $3.09 \%$, respectively $4.94 \%$ ). Among 13 patients with mydriasis or impaired light reflex, six of them died.

The clinical signs with an LR+ between 5 and 10, indicating an increased chance of death with $30-45 \%$, included mydriasis, paraparesis, dysphagia, psychomotor seizures, and delirium. The best predictor of a poor prognosis was mydriasis (LR+ of 9.08). Although some clinical signs such as diminished knee reflexes $[13,107]$ and absent or slow light reflex [107] were earlier postulated to indicate a poor prognosis, we found them to present a moderate increase in death risk of 20-25\%: diminished or absent knee reflex (3.02), globally decreased tendon reflexes (3.46), slow or absent light reflex (4.03). Additionally, we found that anisocoria, acalculia, or seizures could also indicate an increased risk of death.

Interestingly, clinical findings that usually for a neurologist are red flags, such as bilateral Babinski sign, lethargy, stupor, or positive Kerning sign, present a low LR+.

The CSF findings were normal in $44(41.12 \%)$ patients. The rest of the samples presented mainly increased pressure $(10.28 \%)$ and increased proteins $(14.95 \%)$. In most cases that presented cells in the CSF, they were leucocytes (14.95\%). Glucose levels were abnormal in $5.6 \%$ of cases. Trichinella larvae were found in less than one-quarter of the patients $(18.69 \%)$. In patients who died, CSF was normal in $40 \%$, the pressure and glucose levels were normal in $80 \%$, cells were in a normal range in $60 \%$, and proteins were found normal in $70 \%$ of cases. Therefore, the absence of pathological findings in CSF does not exclude a poor prognosis.

Blood eosinophilia was present in $89.58 \%$ of all cases. Nonetheless, approximately half of the patients who died (45.45\%) did not present an increase in eosinophils count. Therefore, it may be postulated that a lack of eosinophilia indicates a poor outcome in patients with a severe symptomatology [100], but further investigation of this paraclinical parameter is necessary.

The CT findings in neurotrichinellosis are non-specific, with multiple hypodensities in the white matter. Nonetheless, a normal CT scan does not exclude CNS involvement. The imaging method of choice should be MRI, which is more sensitive in assessing the extent of brain damage. Border-zone brain lesions may be indicative of neurotrichinellosis. In particular, a patient with eosinophilia and border-zone ischemic lesions should be investigated for idiopathic hypereosinophilic syndrome or brain infection (trichinellosis, filariasis, or schistosomiasis) $[97,105,108]$. As indicated by autopsy reports, the majority of lesions are situated in the white matter. Notably, lesions of the thalamus, cerebellum, and brain stem were less frequent. In addition, rim or nodular enhancement suggests a possible neurotrichinellosis.

Our systematic review included a comprehensive literature search, including articles published in the last 115 years. Nevertheless, our findings are limited by the quality and 
breadth of the data in the case reports, which was not uniform or consistent in all papers. In addition, after 1969, the antihelmintic treatment introduction could have hypothetically modified the clinical picture of cerebral trichinellosis. Nonetheless, the clinical signs reported in neurotrichinellosis after this date were relatively similar to previous cases. Although the number of deaths decreased, it is noteworthy that the clinical signs that we found as indicating a poor prognosis were reported more rarely.

Most importantly, the analysis of case series and reports can suggest hypotheses. Therefore, clinicians should be aware of the large number of cases reported in the literature and the multitude of CNS manifestations. The evidence provided should alert physicians of the possible CNS involvement in trichinellosis infection and some clinical signs that might indicate a poor prognosis. However, further studies are necessary for the diagnostic value of clinical and paraclinical features of neurotrichinellosis to identify severe CNS infection.

Despite the limitations mentioned above, our study represents the first systematic review of the literature published in this field and outlines an accurate state of knowledge of cerebral and meningeal implications in acute Trichinellosis.

Supplementary Materials: The following is available online at https:/ /www.mdpi.com/article/10 .3390/diagnostics11060945/s1/. Table S1: Characteristics of the included case reports.

Author Contributions: Conceptualization, E.C.R.; R.T.; methodology, E.C.R.; R.T.; A.C.; M.S.; investigation, E.C.R.; R.T.; A.C.; M.S.; resources, E.C.R.; R.T.; A.C.; M.S.; data extraction, E.C.R.; R.T.; A.C.; writing—original draft preparation, E.C.R.; R.T.; writing—review and editing, E.C.R.; R.T.; A.C.; M.S.; supervision, E.C.R.; M.S. The first authorship is shared by E.C.R. and R.T. All authors have read and agreed to the published version of the manuscript.

Funding: This research received no external funding.

Institutional Review Board Statement: Not applicable.

Informed Consent Statement: Not applicable.

Data Availability Statement: All data are available as part of the article and Supplementary materials (Table S1).

Conflicts of Interest: The authors declare no conflict of interest.

\section{References}

1. Srikiatkhachorn, A.; Rattanawong, W.; Jongwutiwes, S. Trichinosis. Available online: https://www.medlink.com/articles/ trichinosis (accessed on 18 May 2021).

2. Zenker, F.A. Ueber die Trichinen-Krankheit des Menschen. Arch. Pathol. Anat. Physiol. Klin. Med. 1860, 18, 561-572. [CrossRef]

3. Frothingham, C. A Contribution to the Knowledge of the Lesions caused by Trichina spiralis in Man. J. Med. Res. 1906, 15, 483-490.

4. Pozio, E. World distribution of Trichinella spp. infections in animals and humans. Vet. Parasitol. 2007, 149, 3-21. [CrossRef]

5. Devleesschauwer, B.; Praet, N.; Speybroeck, N.; Torgerson, P.R.; Haagsma, J.A.; De Smet, K.; Murrell, K.D.; Pozio, E.; Dorny, P. The low global burden of trichinellosis: Evidence and implications. Int. J. Parasitol. 2015, 45, 95-99. [CrossRef]

6. Zarlenga, D.; Thompson, P.; Pozio, E. Trichinella species and genotypes. Res. Vet. Sci. 2020, 133, 289-296. [CrossRef]

7. Rostami, A.; Gamble, H.R.; Dupouy-Camet, J.; Khazan, H.; Bruschi, F. Meat sources of infection for outbreaks of human trichinellosis. Food Microbiol. 2017, 64, 65-71. [CrossRef]

8. Pozio, E. Searching for Trichinella: Not all pigs are created equal. Trends Parasitol. 2014, 30, 4-11. [CrossRef]

9. Sofronic-Milosavljevic, L.; Ilic, N.; Pinelli, E.; Gruden-Movsesijan, A. Secretory Products of Trichinella spiralis Muscle Larvae and Immunomodulation: Implication for Autoimmune Diseases, Allergies, and Malignancies. J. Immunol. Res. 2015, $2015,523875$. [CrossRef]

10. Dupouy-Camet, J.K.D.; Murrell, K.D. Management and Diagnosis of Human Trichinellosis; World Organisation for Animal Health Press: Paris, France, 2007; pp. 37-68.

11. Bruschi, F.; Gómez-Morales, M. The translational immunology of trichinellosis: From rodents to humans. In Immune Response to Parasitic Infections_Immunity to Helminths and Novel Therapeutic Approaches; Jirillo, E., Magrone, T., Miragliotta, G., Eds.; Bantham E-Books: Sharjah, United Arab Emirates, 2014; Volume 2, pp. 125-161.

12. Bruschi, F.; Korenaga, M.; Watanabe, N. Eosinophils and Trichinella infection: Toxic for the parasite and the host? Trends Parasitol. 2008, 24, 462-467. [CrossRef]

13. Gray, D.F.; Morse, B.S.; Phillips, W.F. Trichinosis with neurologic and cardiac involvement. Review of the literature and report of three cases. Ann. Intern. Med. 1962, 57, 230-244. [CrossRef] 
14. Dalessio, D.J.; Wolff, H.G. Trichinella Spiralis Infection of the Central Nervous System: Report of a Case and Review of the Literature. Arch. Neurol. 1961, 4, 407-417. [CrossRef] [PubMed]

15. Merritt, H.H.; Rosenbaum, M. Involvement of the nervous system in Trichiniasis. J. Am. Med. Assoc. 1936, 106, 1646-1649. [CrossRef]

16. Gay, T.; Pankey, G.A.; Beckman, E.N. Fatal CNS trichinosis. J. Am. Med. Assoc. 1982, 247, 1024-1025. [CrossRef]

17. Gottstein, B.; Pozio, E.; Nöckler, K. Epidemiology, diagnosis, treatment, and control of trichinellosis. Clin. Microbiol. Rev. 2009, 22, 127-145. [CrossRef]

18. Ryczak, M.; Sorber, W.A.; Kandora, T.F. Difficulties in diagnosing trichinella encephalitis. Am. J. Trop. Med. Hyg. 1987, 36, 573-575. [CrossRef]

19. Bruschi, F.; Brunetti, E.; Pozio, E. Chapter 19-Neurotrichinellosis. In Handbook of Clinical Neurology; Garcia, H.H., Tanowitz, H.B., Del Brutto, O.H., Eds.; Elsevier: Amsterdam, The Netherlands, 2013; Volume 114, pp. 243-249.

20. Fourestie, V.; Douceron, H.; Brugieres, P.; Ancelle, T.; Lejonc, J.L.; Gherardi, R.K. Neurotrichinosis: A cerebrovascular disease associated with myocardial injury and hypereosinophilia. Brain 1993, 116, 603-616. [CrossRef]

21. Kociecka, W. Trichinellosis: Human disease, diagnosis and treatment. Vet. Parasitol. 2000, 93, 365-383. [CrossRef]

22. WHO. Risk-Based Examples and Approach for Control of Trichinella spp. and Taenia Saginata in Meat. Available online: https:/ / www.who.int/publications/i/item/9789240012431 (accessed on 19 May 2021).

23. Gajadhar, A.A.; Noeckler, K.; Boireau, P.; Rossi, P.; Scandrett, B.; Gamble, H.R. International Commission on Trichinellosis: Recommendations for quality assurance in digestion testing programs for Trichinella. Food Waterborne Parasitol. 2019, 16, e00059. [CrossRef]

24. Moher, D.; Liberati, A.; Tetzlaff, J.; Altman, D.G. Preferred reporting items for systematic reviews and meta-analyses: The PRISMA statement. Ann. Intern. Med. 2009, 151, 264-269. [CrossRef]

25. Murad, M.H.; Sultan, S.; Haffar, S.; Bazerbachi, F. Methodological quality and synthesis of case series and case reports. BMJ Evid. Based Med. 2018, 23, 60-63. [CrossRef]

26. McGee, S. Simplifying likelihood ratios. J. Gen. Intern. Med. 2002, 17, 646-649. [CrossRef]

27. Van Cott, J.M.; Lintz, W. Trichinosis. JAMA 1914, 680. [CrossRef]

28. Lintz, W. Trichinosis and the Cerebrospinal Fluid. Am. J. Med. 1916, 66, 1856. [CrossRef]

29. Elliott, A. Trichinosis. Report of a Case with Trichina Larvae in the Spinal Fluid. JAMA 1916, 66, 504. [CrossRef]

30. Salzer, B. A Study of an Epidemic of Fourteen Cases of Trichinosis with Cures by Serum Therapy. JAMA 1916, 67, 579. [CrossRef]

31. Cummins, W.T.; Carson, G.R. A Case of Trichinosis with Embryo in the Spinal Fluid. JAMA 1916, 66, 1856. [CrossRef]

32. Bloch, L.; Hassin, G.B. Trichinosis Complicated by Encephalitis. Med. Rec. 1917, 91, 537.

33. Meyer, J. Trichinosis: A report of three cases simulating meningitis, with the findings of Trichina larvae in spinal fluid. J. Am. Med. Assoc. 1918, 70, 588-590. [CrossRef]

34. Sterling, W. Nervous Disturbances in Trichinosis. Rev. Neurol. 1935, 1, 435.

35. Horlick, S.S.; Bicknell, R.E. Trichiniasis with Widespread Infestation of Many Tissues. N. Engl. J. Med. 1929, 201, 816-832. [CrossRef]

36. Hassin, G.B.; DIAMOND, I.B. Trichinosis encephalitis: A pathologic study. Arch. Neurol. Psychiatry 1926, 15, 34-47. [CrossRef]

37. Salan, J.; Schwartz, B. Trichinosis with involvement of the central nervous system. J. Am. Med. Assoc. 1928, 90, 611. [CrossRef]

38. Dandy, W. Practice of Surgery; W.F. Prior \& Company: Hagerstown, MD, USA, 1929.

39. Stoll, H.F. Trichinosis: Report of Two Cases Presenting Diplopia and One, Polyserositis. JAMA 1930, 92, 791. [CrossRef]

40. Walker, A.T. Trichiniasis: Report of an outbreak caused by eating trichinous bear meat in the form of jerky. J. Am. Med. Assoc. 1932, 98, 2051-2053. [CrossRef]

41. Filinski, W. Pathological Changes in the Central Nervous System in Trichinosis. Pol. Arch. Med. Werwnet 1932, $10,451$.

42. Pund, E.R.; Mosteller, R. Trichinosis: Demonstration of the parasites in the brain. J. Am. Med. Assoc. 1934, 102, 1220-1222. [CrossRef]

43. Gordon, M.B.; Cares, R.; Kaufman, B. Encephalitis and myocarditis in a fatal case of trichinosis. Report of a case in a fourteenyear-old girl. J. Pediatrics 1935, 6, 667-675. [CrossRef]

44. Spink, W.W. Cardiovascular complications of Trichinosis. Arch. Intern. Med. 1935, 56, 238-249. [CrossRef]

45. Blumer, G. Trichinosis, with Special Reference to Changed Conceptions of the Pathology and Their Bearing on the Symptomatology. N. Engl. J. Med. 1936, 214, 1229-1235. [CrossRef]

46. Most, H.; Milton, M. Trichiniasis involving the nervous system: A clinical and neuropathologic review, with report of two cases. Arch. Neurol. Psychiatry 1937, 37, 589-616. [CrossRef]

47. Evers, L.B. Manifestations of Trichiniasis in the central nervous system: Report of a case with larvae in the spinal fluid. Arch. Intern. Med. 1939, 63, 949-956. [CrossRef]

48. Houston, J.C. Trichiniasis with cerebral symptoms report on two cases. Lancet 1941, 238, 397-398. [CrossRef]

49. Sheldon, J.H. An outbreak of trichiniasis: In Wolverhampton district. Lancet 1941, 237, 203-205. [CrossRef]

50. Wyrens, R.G.; Tillisch, J.H.; Magath, T.B. Trichinosis: Report of ninteen cases of clinical infection and twenty-one cases of asymptomatic infection. J. Am. Med. Assoc. 1941, 117, 428-432. [CrossRef]

51. Campbell, W. Psychoses with Trichinosis. Rhode Isl. Med. J. 1947, 30, 2.

52. Battle, J.J.; Feinberg, D.H. Neurologic Complications of Trichinosis. Easton Hosp. Bull. 1948, 1, 7-11. 
53. MacAndrew, M.; Davis, E. Trichiniasis presenting with foot-drop and facial palsy. Lancet 1948, 251, 141. [CrossRef]

54. Skinner, J.C. Neurologic Complications of Trichinosis. N. Engl. J. Med. 1948, 238, 317-319. [CrossRef] [PubMed]

55. Bruno MS, G.M. Meningoencephalitis Due to Trichinella Spiralis. N. Y. J. Med. 1950, 49, 707.

56. McCabe, E.S.; Zatuchni, J. Fulminating trichiniasis. Am. J. Dig. Dis. 1951, 18, 205-208. [CrossRef] [PubMed]

57. Davis, W.M.; Most, H. Trichinosis: Case report with observations of the effect of adrenocorticotropic hormone. Am. J. Med. 1951, 11, 639-644. [CrossRef]

58. Helfand, M.; Houck, K.H.; Weissman, F.M. Trichinosis as a cause of encephalitis (case report and review of the literature). Dis. Nerv. Syst. 1952, 13, 242-246.

59. Brimblecombe, F.S.; Keech, M. Presumed dermatomyositis with cardiomegaly, trichiniasis and epilepsy. Proc. R Soc. Med. 1952, 45, 398-399.

60. Scott, R.A.; Johnson, R.E.; Holzman, D. Trichinosis with neurologic and mental manifestations. N. Engl. J. Med. 1952, 247, 512-514. [CrossRef] [PubMed]

61. Hurd, R.W. Focal cerebral injury due to trichinella spiralis. J. Nerv. Ment. Dis. 1953, 117, 526-536. [CrossRef]

62. Roehm, D.C. Trichinosis; report of case manifesting myocarditis, encephalitis and radial neuritis; response to ACTH; review of literature regarding the erythrocyte sedimentation rate. Ann. Intern. Med. 1954, 40, 1026-1040. [CrossRef] [PubMed]

63. Semple, A.B.; Davies, J.B.M.; Kershaw, W.E.; Hill, C.A.S. An Outbreak of Trichinosis in Liverpool in 1953. Br. Med. J. 1954, 1, 1002-1006. [CrossRef]

64. Freedman, S.O.; Clamen, M. A case of trichinosis simulating meningitis. Can. Med. Assoc. J. 1954, 71, 160-161. [PubMed]

65. Marcus, S.; Miller, R.V. An atypical case of trichinosis with report of electromyographic findings. Ann. Intern. Med. 1955, 43, 615-622. [CrossRef] [PubMed]

66. Kershaw, W.E.; St. Hill, C.A.; Semple, A.B.; Davies, J.B.M. The distribution of the larvae of trichinella spiralis in the muscles, viscera and central nervous system in cases of trichinosis at liverpool in 1953, and the relation of the severity of the illness to the intensity ofinfection. Ann. Trop. Med. Parasitol. 1956, 50, 355-361. [CrossRef] [PubMed]

67. Leitner, M.J.; Grynkewich, S.E. Encephalopathy associated with trichinosis treatment with ACTH and. Am. J. Med. Sci. 1958, $236,546-550$.

68. Snape, W.J.; Nardi, M.; Barse, F. Persistent Mental Aberration Associated with Trichinosis: Case Report. J. Med. Soc. N. J. 1956, $53,309$.

69. Guattery, J.M.; Milne, J.; House, R.K. Observations on hepatic and renal dysfunction in trichinosis: Anatomic changes in these organs occurring in cases of trichinosis. Am. J. Med. 1956, 21, 567-582. [CrossRef]

70. Meltzer, L.E.; Bockman, A.A. Trichinosis involving the central nervous system: Treatment with corticotropin (acth) and cortisone. J. Am. Med. Assoc. 1957, 164, 1566-1569. [CrossRef]

71. Terplan, K.; Kraus, R.; Barnes, S. Eosinophilic meningo-encephalitis, with predominantly cerebellar changes caused by Trichinella infection. J. Mt. Sinai Hosp. N. Y. 1957, 24, 1293-1309.

72. Chase, G.O. Death due to eosinophilic myocarditis related to trichinosis: Report of a case. J. Am. Med. Assoc. 1957, 165, 1826-1829. [CrossRef]

73. Mavor, H. Focal central-nervous-system involvement associated with trichinosis; report of a case. N. Engl. J. Med. 1958, 258, 648-650. [CrossRef] [PubMed]

74. Levine, J. A case of trichinosis with encephalitis. N. Y. State J. Med. 1958, 58, 578-579.

75. Greenstein, N.M.; Steinberg, D. The Prompt and Effective Response of Trichinosis to Corticotropin. Am. J. Dis. Child. 1958, 95, 261-269. [CrossRef]

76. Perot, P.; Lloyd-Smith, D.; Libman, I.; Gloor, P. Trichinosis encephalitis: A study of electroencephalographic and neuropsychiatric abnormalities. Neurology 1963, 13, 477-485. [CrossRef] [PubMed]

77. Barr, R. Human trichinosis: Report of four cases, with emphasis on central nervous system involvement, and a survey of 500 consecutive autopsies at the Ottawa Civic Hospital. Can. Med. Assoc. J. 1966, 95, 912-917.

78. Kennedy, F.B.; Rege, V.B. Trichinosis: Hemiplegia and Liver Involvement. Arch. Intern. Med. 1966, 117, 108-112. [CrossRef]

79. Corridan, J.P.; Gray, J.J. Trichinosis in South-west Ireland. Br. Med. J. 1969, 2, 727-730. [CrossRef]

80. Kramer, M.D.; Aita, J.F. Trichinosis with central nervous system involvement: A case report and review of the literature. Neurology 1972, 22, 485-491. [CrossRef]

81. Davis, M.J.; Cilo, M.; Plaitakis, A.; Yahr, M.D. Trichinosis: Severe myopathic involvement with recovery. Neurology 1976, 26, 37-40. [CrossRef] [PubMed]

82. Gross, B.; Ochoa, J. Trichinosis: Clinical report and histochemistry of muscle. Muscle Nerve 1979, 2, 394-398. [CrossRef] [PubMed]

83. Evans, R.W.; Patten, B.M. Trichinosis associated with superior sagittal sinus thrombosis. Ann. Neurol. 1982, 11, 216-217. [CrossRef]

84. Froscher, W.; Gullotta, F.; Saathoff, M. Chronic trichinellosis and neuromuscular diseases: Clinical, serological and therapeutic observations. Dtsch. Med. Wochenschr. 1982, 107, 1432-1437. [CrossRef]

85. Lyon-Caen, O.; Hauw, J.J.; Vitoux, J.F. Trichinosis of the central nervous system. One case. Nouv. Presse Med. 1982, 11, $2343-2346$.

86. Ancelle, T.; Dupouy-Camet, J.; Heyer, F.; Faurant, C.; Lapierre, J. Outbreak of Trichinosis due to horse meat in the Paris area. Lancet 1985, 326, 660. [CrossRef]

87. Ellrodt, A.; Halfon, P.; Bras, P.; Halimi, P.; Bourée, P.; Dési, M.; Caquet, R. Multifocal Central Nervous System Lesions in Three Patients With Trichinosis. Arch. Neurol. 1987, 44, 432-434. [CrossRef] 
88. Vega, E.; Martinez, G. Central nervous system complication in trichinosis. Rev. Chil. Pediatr. 1987, 58, 478-480. [CrossRef]

89. Kreel, L.; Poon, W.S.; Nainby-Luxmoore, J.C. Trichinosis diagnosed by computed tomography. Postgrad. Med. J. 1988, 64, 626-630. [CrossRef] [PubMed]

90. Lopez-Lozano, J.J.; Merino, J.G.; Liano, H. Bilateral facial paralysis secondary to trichinosis. Acta Neurol. Scand. 1988, 78, 194-197. [CrossRef] [PubMed]

91. Louthrenoo, W.; Mahanuphab, P.; Sanguanmitra, P.; Thamprasert, K. Trichinosis mimicking polymyositis in a patient with human immunodeficiency virus infection. Rheumatology 1993, 32, 1025-1026. [CrossRef]

92. El Koussa, S.; Chemaly, R.; Fabre-Bou Abboud, V.; Tamraz, J.; Haddad, N. Trichinosis and cerebral sino-venous thrombosis. Rev. Neurol. 1994, 150, 464-466.

93. Clausen, M.R.; Meyer, C.N.; Krantz, T.; Moser, C.; Gomme, G.; Kayser, L.; Albrectsen, J.; Kapel, C.M.O.; Bygbjerg, I.C. Trichinella infection and clinical disease. QJM Mon. J. Assoc. Physicians 1996, 89, 631-636. [CrossRef] [PubMed]

94. Feydy, A.; Touze, E.; Miaux, Y.; Bolgert, F.; Martin-Duverneuil, N.; Laplane, D.; Chiras, J. MRI in a case of neurotrichinosis. Neuroradiology 1996, 38, S80-S82. [CrossRef]

95. De Graef, M.; Smadja, P.; Benis, J.; Turpin, F.; Liouane, M.; Viaud, B.; Ruffie, P.; Bourbotte, G.; Bonafé, A. Neurotrichinosis: A case report with MR evaluation. J. Radiol. 2000,81,817-819.

96. Knezević, K.; Turkulov, V.; Canak, G.; Lalosević, V.; Tomić, S. Neurotrichinosis. Med. Pregl. 2001, 54, $483-485$.

97. Gelal, F.; Kumral, E.; Dirim Vidinli, B.; Erdogan, D.; Yucel, K.; Erdogan, N. Diffusion-weighted and conventional MR imaging in neurotrichinosis. Acta Radiol. 2005, 46, 196-199. [CrossRef] [PubMed]

98. Langner, S.; Kirsch, M.; Khaw, A.V.; Stein, T.; Vogelgesang, S.; Hosten, N. Diffusion-weighted imaging proves watershed infarction in neurotrichinosis. Eur. J. Radiol. Extra 2007, 64, 45-48. [CrossRef]

99. Madariaga, M.G.; Cachay, E.R.; Zarlenga, D.S. Case report: A probable case of human neurotrichinellosis in the United States. Am. J. Trop. Med. Hyg. 2007, 77, 347-349. [CrossRef] [PubMed]

100. Neghina, R.; Neghina, A.M.; Marincu, I.; Iacobiciu, I. Reviews on Trichinellosis (II): Neurological Involvement. Foodborne Pathog. Dis. 2011, 8, 579-585. [CrossRef]

101. McDonald, C.M.; Tai, P.; Krings, T. Pearls and oy-sters: A rare case of neurotrichinosis with MRI. Neurology 2014, 82, e30-e32. [CrossRef]

102. Moscatelli, G.; Moroni, S.; Bournissen, F.G.; Altcheh, J.; Nora, S.; Arturo, D.M.; Gabriela, M. Neurotrichinosis in a pediatric patient. Pediatric Infect. Dis. J. 2014, 33, 115-117. [CrossRef]

103. Batzlaff, C.M.; Pupaibool, J.; Rizwan Sohail, M. Acute renal failure associated with albendazole therapy in a patient with trichinosis. BMJ Case Rep. 2014. [CrossRef]

104. Dalcin, D.; Zarlenga, D.S.; Larter, N.C.; Hoberg, E.; Boucher, D.A.; Merrifield, S.; Lau, R.; Ralevski, F.; Cheema, K.; Schwartz, K.L.; et al. Trichinella Nativa Outbreak with Rare Thrombotic Complications Associated with Meat from a Black Bear Hunted in Northern Ontario. Clin. Infect. Dis. 2017, 64, 1367-1373. [CrossRef]

105. Rosca, E.C.; Simu, M. Border zone brain lesions due to neurotrichinosis. Int. J. Infect. Dis. 2018, 67, 43-45. [CrossRef]

106. Mitrović, N.; Milošević, B.; Urošević, A.; Nikolić, N.; Dakić, Z.; Nikolić, I.; Korać, M. Severe trichinellosis with neurological involvement-neurotrichinellosis: A case report. Vet. Glas. 2019, 73, 178-186. [CrossRef]

107. Lintz, W. Trichinosis with involvement of the central nervous system. J. Am. Med. Assoc. 1928, 90, 997. [CrossRef]

108. Mangla, R.; Kolar, B.; Almast, J.; Ekholm, S.E. Border zone infarcts: Pathophysiologic and imaging characteristics. Radiographics 2011, 31, 1201-1214. [CrossRef] [PubMed] 